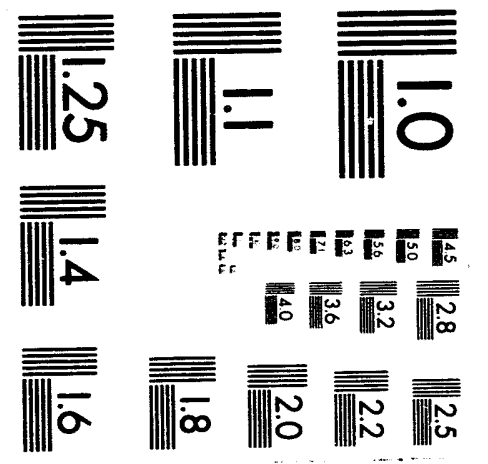



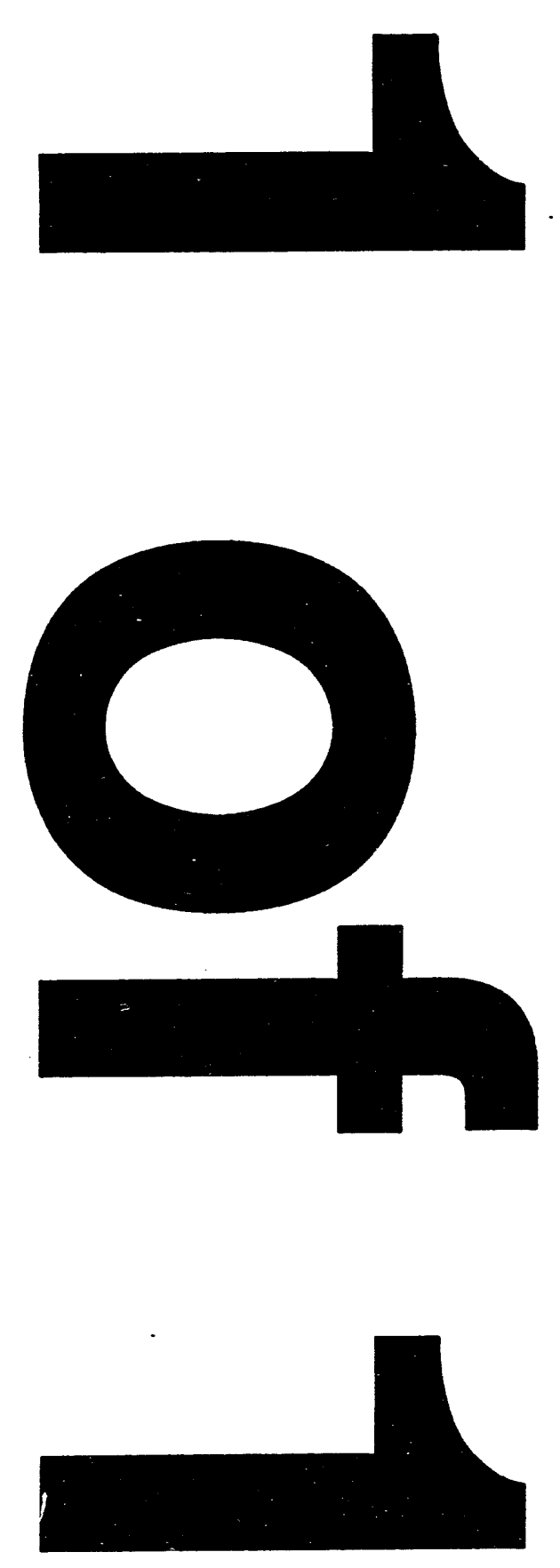
$\frac{12}{1-2} 89485(1)$

UCRL-ID-115718

\title{
Vulnerability of Hot LX-17 to Lightning Strikes on Exposed Detonator and Actuator Cables
}

\author{
H. H. Chau \\ J. E. Osher \\ W. G. Von Holle \\ R. S. L : \\ K. Moua
}

December 1993

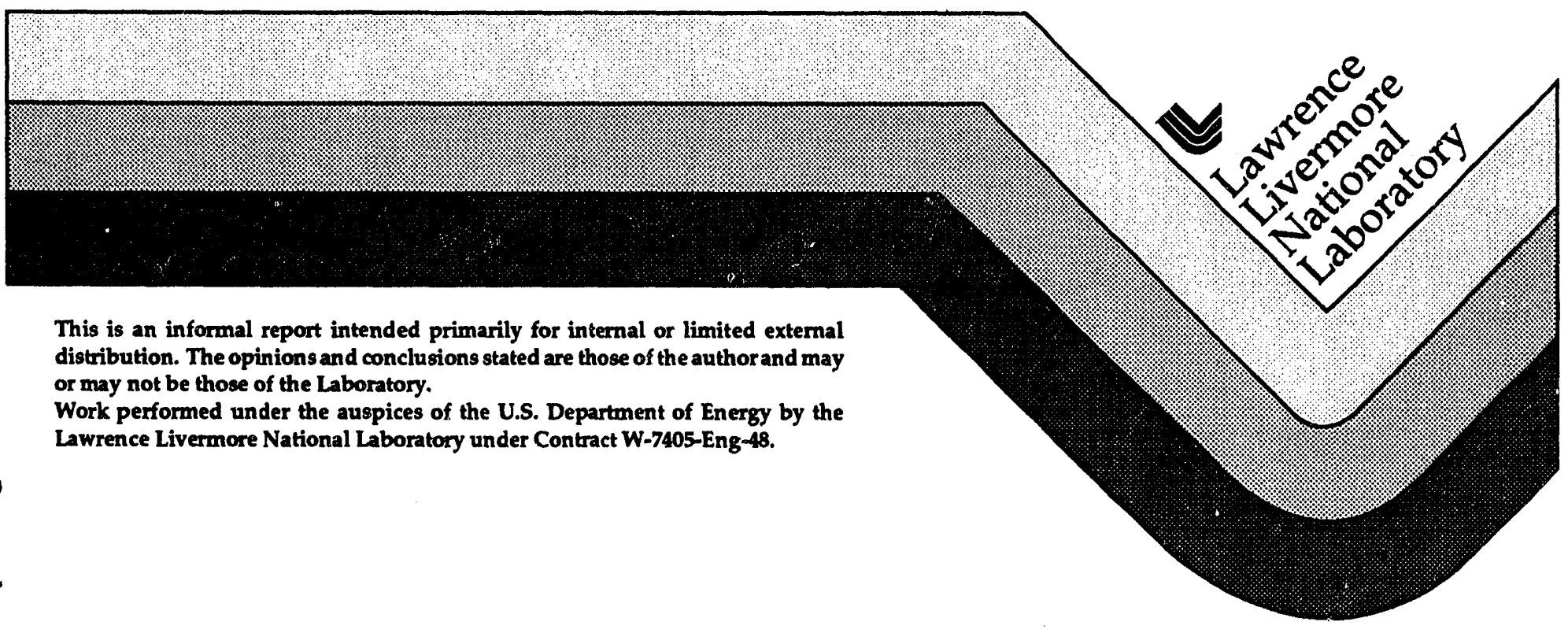




\section{DISCLAIMER}

This document was prepared as an account of work sponsored by an agency of the United States Government. Neither the United States Government nor the University of California nor any of their employees, makes any warranty, express or implied, or assumes any legal liability or responsibility for the accuracy, completeness, or usefulness of any information, apparatus, product, or process disclosed, or represents that its use would not infringe privately owned rights. Reference herein to any specific commercial products, process, or service by trade name, trademark, manufacturer, or otherwise, does not necessarily constitute or imply its endorsement, recommendation, or favoring by the United States Government or the University of California. The views and opinions of authors expressed herein do not necessarily state or reflect those of the United States Government or the University of California, and shall not be used for advertising or product endorsement purposes.

This report has been reproduced directly from the best available cony.

Available to DOE and DOE contractors from the Office of Scientific and Technical Information P.O. Box 62, Oak Ridge, TN 37831

Prices available from (615) 576.8401, FTS 626-8401

Available to the public from the National Technical Information Service

US. Department of Commerce 5285 Port Royal Rd., Springfield, VA 22161 


\title{
VULNERABILITY OF HÓT LX-17 TO LIGHTNING STRIKES ON EXPOSED DETONATOR AND ACTUATOR CABLES
}

\author{
H. H. Chau, J. E. Osher, W. G. Von Holle, \\ R. S. Lee, K. Moua \\ Lawrence Livermore National Laboratory
}

\begin{abstract}
Capacitor bank discharges with peak currents up to $700 \mathrm{kA}$ were used to explode test sections of detonator cable and launch the dielectric material on top of the exploding conductor as a fast flyer plate. Velocity of the launched material, pressure profiles from the impact of the launched material and impact marks formed in aluminum witness plates were used to study the stimulus that could be transmitted to high explosive in the vicinity of the exploding cable. To quantify the risk of initiating the main charge or booster insensitive high explosive (IHE) in a weapon, one must know the threshold stimulus required for shock initiation. LX-17 samples, heated to temperatures up to $250^{\circ} \mathrm{C}$ were impacted by 3 to $10-\mathrm{mm}$-wide strips of $0.12-\mathrm{mm}$-thick Kapton to determine the initiation threshold velocity at ambient and elevated temperatures. The strips simulate the impact of the cover coat of a flat detonator cable which has been exploded by a lightning strike. The data allow us to assess the likelihood that a lightning strike on the cable would be able to initiate a detonation of the LX-17 main charge.
\end{abstract}

\section{Lightning Discharge Simulations}

\section{Lightning Hazards}

A lightning strike is a natural source of highpower electrical energy which has the potential for energizing electrical conductors which are in proximity to the high explosive (HE) charge of a nuclear weapon. The outcome of such an event will depend on (1) the severity of the strike, (2) the type of HE in the weapon, (3) whether the detonators are configured so that detunator function will transfer the detonation to the booster and main charge, (4) the extent of electrical coupling between the lightning strike and the conductors, (5) the geometry of the conductors and surrounding inert materials in relation to the $\mathrm{HE}$ surface, and (6) other abnormal environments which may exist at the time of the lightning strike, e.g. high temperature from a fire or damaged $\mathrm{HE}$ from a severe impact. We will consider systems which are similar to the W87 and W89 designs.

These designs have some unique safety features which greatly mitigate the effect of a lightning strike. With reference to item (2) above, we assume that a lightning strike which couples into the detonator cables will detonate the initiating pelle, but because of the unique mechanical safe and arm system used by the W87 and W89 detonators, detonation of the initiating pellet will not initiate the booster unless the detonator has been armed by a unique signal.

The W87 and W89 designs use insensitive high explosive for both the booster and main charge. The main charge material is LX-17 (92.5\%/7.5\% TATB/Kel F) and the booster is Ultrafine TATB at a density of $1.80 \mathrm{~g} / \mathrm{cc}$. The use of IHE means that a much more powerful stimulus is required for initiation, compared to conventional HE. IHE is also much more tolerant of extreme abnormal environments than conventional HE. In the study reported here, we will consider the effect of a lightning strike coupling directly into the detonator cables, into the conducting actuator cables which operate the mechanical safe and arm discriminator, and a high-intensity electrical discharge directly across the surface of bare LX-17.

\section{Lightning Strike Waveform}

We have chosen the lightning test current waveform specified in MIL-STD-1757A as a baseline lightning strike. The waveform, shown schematically in Fig. 1, represents a negative lightning strike in the 99th percentile of severity or a positive lighening strike in the 90 th percentile. The features relevant to our study are the fast risetime $\left(1.4 \times 10^{11} \mathrm{~A} / \mathrm{s}\right)$ and the $200 \mathrm{kA}$ peak current which decays linearly over $0.5 \mathrm{~ms}$. at a current of $200 \mathrm{kA}$ or greater, the cable conductors and actuator cables will explode ir a few microseconds, and over this period, the current in our assumed baseline strike will be nearly constant.

\section{Experimental Simulation of Lightning Strikes}

To simulate a lighming strike we have chosen a capacitor discharge waveform. Detonator cables were electrically exploded by discharging a $100 \mathrm{kV}, 87 \mathrm{~kJ}$ capacitor bank into cable lengths ranging from $2.5 \mathrm{~cm}$ to $23 \mathrm{~cm}$. A waveform from one of our tests is compared with the MII-STD waveform in Fig. 2., The capacitor bank waveform has a faster rise and burst occurs at a higher current than the MIL-STD 
waveform, so the experiment simulates a more severe lightning strike. When a conductor is exploded electrically, most of the energy deposition occurs near the time of burst, so the fact that the capacitor discharge waveform does not look like the assumed lightning waveform after burst is not important. The important parameters are the current risetime and burst current. Details of the experimental arrangements are given in Osher, el al. (1993) and will not be repeated here.

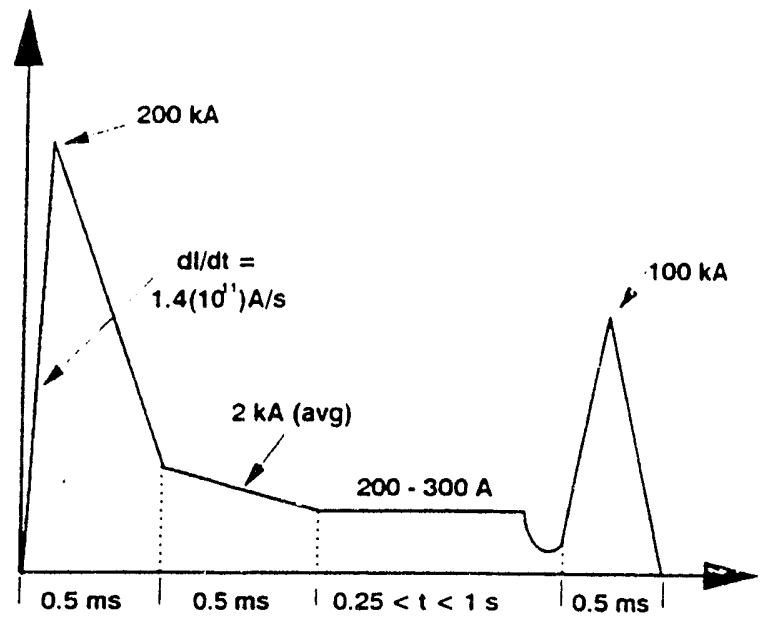

Figure 1. Schematic of waveform for 90 th percentile negative lightning, from MIL-STD-1757A.

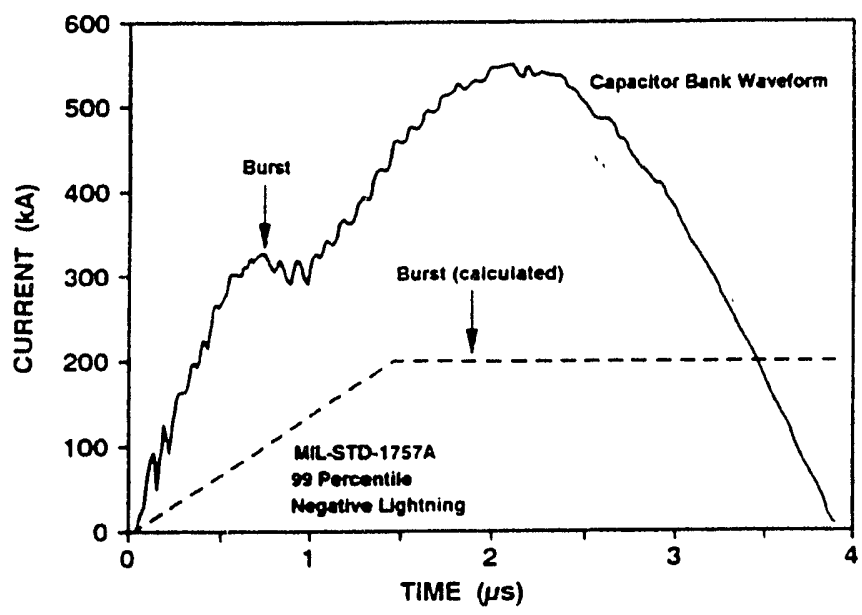

Figure 2. Companson of lightning waveform and cable burst using a capacitor discharge.

Figure 3 gives an exploded view of the construction of the two types of detonator cables that were sudied. The W87 cables have relatively narrow conductors, 3.17-mm-wide, and a 0.0762-mm-thick cover coat. The W89-type cables, designed to have lower inductance, have conductors $15 \mathrm{~mm}$ wide with a 0.0508-mm-thick cover coat.

Our initial goal was to see if the dielectric cover coat could be launched to velocities which could initiate $\mathrm{LX}-17$ at room temperature $\left(20^{\circ} \mathrm{C}\right)$. To achieve velocities in a range which could potentially initiate room-temperature $L X-17$, we fired most of our shots with a charging voltage of $60 \mathrm{kV}$. Quantities of interest in these experiments included cover coat (flyer) velocity, the current path through the detonator cables, the impact footprint of the flyer, and the pressure pulse produced by the flyer impact.

Flyer velocity was measured with a Fabry.

Perot (F-P) laser velocimeter. Current paths were studied where the bank was connected to the top conductor only, the bottom conductor only, and both top and bottom conductors in parallel.

Impact footprints were studied dynamically by recording the impact of the flyer on a glass target with a streak camera, and statically by allowing the flyer to strike an aluminum witness block.

The pressure pulse was measured by a technique where the flyer was allowed to strike a $\mathrm{LiF}$ crystal where the impact face was covered by a 12 micron-thick aluminum foil. A F-P velocimeter measured the velocity of the LiF/Al interface as a function of time and the pressure pulse was calculated from the LiF Hugoniot curve.

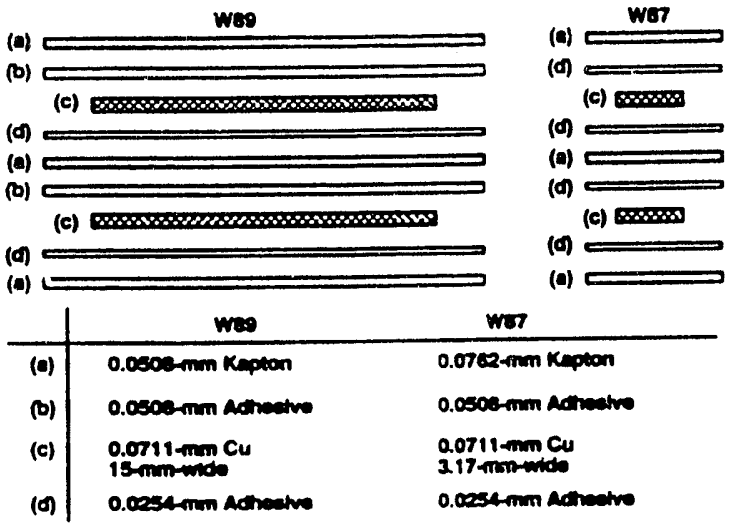

Figure 3. Exploded view of detonator cable cross sections for W89 and W87 cables.

\section{Lightning Simulation Results (no HE) \\ Experimental results will be summarized here.}

For detailed tabulations, refer to Osher el al. (1993).

The $2.5-\mathrm{cm}$ long cables gave the highest cover coat velocities, $(-3.5 \mathrm{~km} / \mathrm{s}$ with $2-\mathrm{mm}$ flight, $\sim 7.3 \mathrm{~km} / \mathrm{s}$ with $7-\mathrm{mm}$ flight) but the currents were unrealistically high. The 10-cm-long cables had burst currents of about 300 $\mathrm{kA}, 50 \%$ higher than the 99-percentile negative lightning strike, and cover coat velocities were 2.9-4.3 $\mathrm{km} / \mathrm{s}$ and $4.5-6.8 \mathrm{~km} / \mathrm{s}$ for flights of 2 and $7 \mathrm{~mm}$. respectively. Cables of length $15 \mathrm{~cm}$ and $23 \mathrm{~cm}$ gave 
lower burst currents and velocities in the $1-3 \mathrm{~km} / \mathrm{s}$ range.. The dependence of burst current on cable length is an arifact of the capacitor bank source, which is sensitive to load impedance. A lightning strike is a very stiff source and cable current would be independent of length until voltages reached the point where breakdown occurs through the cover coat.

Comparing the results where the current was initially connected to the top, bottom or both conductors gave interesting results. Current and voltage waveforms showed that when the current passed through only one conductor, high voltage breakdown would take place to the other conductor near burst, resulting in a weak burst. The current would then be shared between the two conductors and the second conductor would subsequently burst. Highest cover coat velocities were observed when the current was initially connected to the bottom conductor or to both conductors.

A streak record of the impact of the flyer is shown in Fig. 4. The impact shows a strong transverse structure, with lobes of material out toward the edges of the flyer. This structure was also observed when the cover coat was allowed to strike an aluminum witness plate.
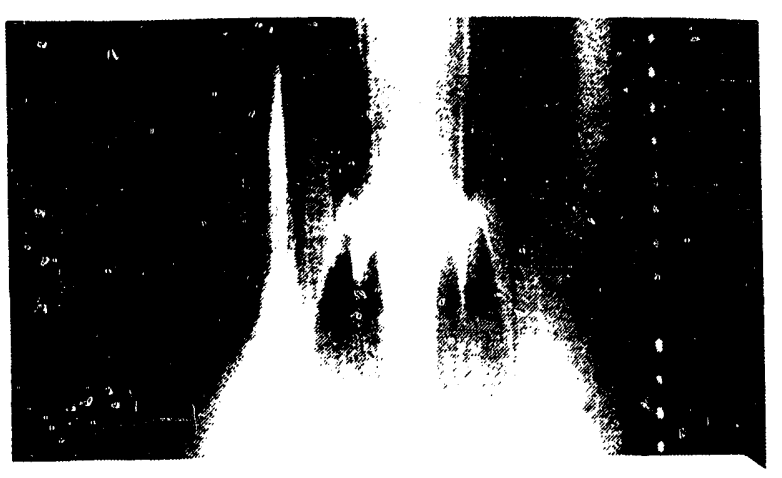

Figure 4. Streak record of the impact of the cover coat from an exploded W89-type cable. Time runs from top to bottom in the photograph and the time between the spots on the right is 100 nanosyconds.

Measurements of the pressure pulse produced by flyer impact were made using the $\mathrm{LiF}$ technique discussed above. The resulis were not very consistent, perhaps due to the structure we observed in the flyer impact. One would expect that a difierent pressure profile would be observed if the laser spot were directly under a lobe than if the laser spot were located midway between the center and the lobe. Some of the observed spread in cover coat velocity may be due to the transverse structure as well.
Comparing the observed velocities and pressure pulses with thin pulse flyer initiation data for TATB formulations (Honodel et al. 1981), it appeared that with proper standoff between the cables and the explosive, the cover coat of the W89 cables was being launched with sufficient velocity to shock initiate hot $\left(250^{\circ} \mathrm{C}\right) \mathrm{LX}-17$ and Ultrafine TATB (UFTATB) booster explosive, and at room temperature could shock initiate UFTATB but not LX-17. The burst currents were above the 99-percentile negative lightning peak current, but were comparable to or somewhat smaller than the peak currents for 99 percentile positive lightning.

The narrower W87 cables gave a higher cover coat velocity for the same current input, in some cases exceeding the shock initiation threshold velocity for both hot and room temperature UFTATB and LX-17. However, exceeding the threshold velocity is a necessary, but not sufficient condition for shock initiation.

The impact area must aiso exceed a critical area. For circular flyers, the threshold velocity for initiation rises sharply below $1.27 \mathrm{~cm}$ diameter (Jackson et al. 1976), and one would expect a similar critical width for strip flyers. In addition, the structure observed in the cover coat impacts may make them less effective for shock initiation. Further experiments, involving live $\mathrm{HE}$, are required to quantify the risk from lightning coupling to detonator cables.

\section{Actuator Cable Studies}

Steel actuator cables which operate the unique signal discriminator offer another conducting path to the FIE. Experiments were conducted where actuator cables in direct contact with hot $\mathrm{HE}$ were exploded with peak currents over $600 \mathrm{kA}$. Neither LX-17 nor UFTATB detonated (Osher et al. 1993).

\section{Surface Discharge Studies}

Experiments were conducted where intense surface arc discharges with linear current densities over $700 \mathrm{kA} / \mathrm{cm}$ were conducted over the surface of hot UFTA'TB without producing a detonation (Osher es al. 1993).

\section{Velocity Threshold for Strip Flyers Impacting Hot LX-17}

The exploding cable experiments described above were useful for understanding the shock stimuli delivered to adjacent material, but a better-defined strip impactor is needed to do meaningful experiments on the response of high explosive to strip impacts. We devised an experimental procedure for launching strips of Kapton dielectric of known velocity at a $\mathrm{HE}$ target 
which could be heated to a desired temperature. The well-defined impacts allow us to relate the HE response to theory and to compare the results with other impact experiments, e.g. gun experiments.

\section{Electric Gun for Launching Strips}

To launch the strips we used a device that we have used extensively for HE shock initiation experiments, which we call an electric gun (Weingart et al. 1976). The electric gun has been described in detail in the literature (Chau et al. 1979), so we will not give details here. The electric gun operates by discharging a capacitor bank through a thin aluminum foil which subsequently explodes and drives a sheet of dielectric material to velocities of several $\mathrm{km} / \mathrm{s}$. The Al bridge foil we used was $5.08 \mathrm{~cm}$ long, $1.27 \mathrm{~cm}$ wide and 0.0508 $\mathrm{mm}$ thick. The bridge foil and flyer material were laminated into a flat-plate transmission line assembly which was clamped into the transmission line leading from the capacitor bank.

The Kapton flyer plate material was $0.127 \mathrm{~mm}$ thick. The barrel which defined the flyer plate dimensions was $10 \mathrm{~mm}$ wide and $5 \mathrm{~cm}$ long. The flyer strips were all $5 \mathrm{~cm}$ long, but the widths were 3,7 and $10 \mathrm{~mm}$. The strip width was varied by imposing a Ta barrier which passed the desired width strip and stopped the unwanted material. Total standoff distance between the surface of the unlaunched flyer and the bottom of the target was $12.7 \mathrm{~mm}$. The experimental arrangement is shown in Fig. 5.

\section{Method for Heating HE Samples}

The worst-case scenario for lightning to couple into detonator cables is that the HE would be sensitized by heating in a fire before the lightning strike. We wished to determine the shock initiation threshold for strip impacts from room temperature up to $250^{\circ} \mathrm{C}$, so it was necessary to construct an oven and transport system to position the hot HE over the electric gun, as is shown schematically in Fig. 6.

The LX-17 samples, $5.08 \mathrm{~cm}$ long with a 2.54 $\mathrm{cm}$-square cross section, were mounted into a steel block $6.72 \mathrm{~cm}$ long with a $5.08-\mathrm{cm}$-square cross section. Thermocouples were mounted in several locations around the block to monitor temperature.

The heating oven was constructed from two cylindrical heating bands mounted together to form a tubular oven. A programmable controller allowed the oven temperature to be ramped up to a desired level and maintained to allow the sample to reach equilibrium. Power to the oven was transferred through a highvoltage relay, which isolated the oven when the shot was fired.

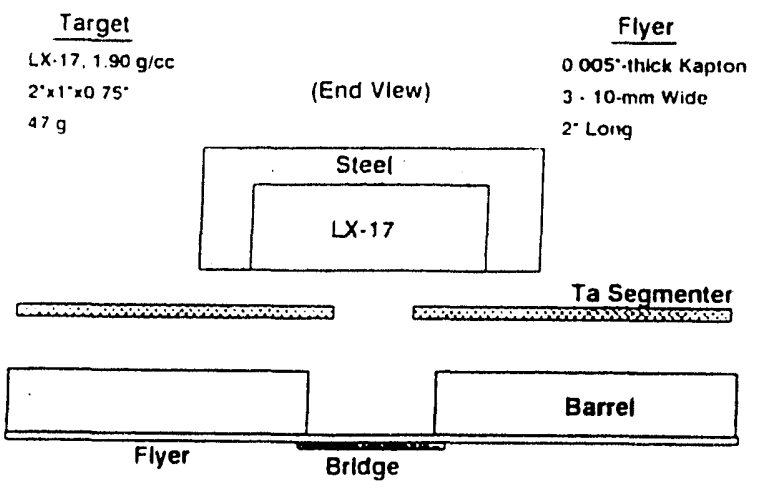

Figure 5. Experimental arrangement for producing strip flyers. The barrel is $10 \mathrm{~mm}$ across, producing a $10-\mathrm{mm}$ wide strip flyer. The Ta segmenter only allows the portion of the flyer defined by the open slit to reach the target.

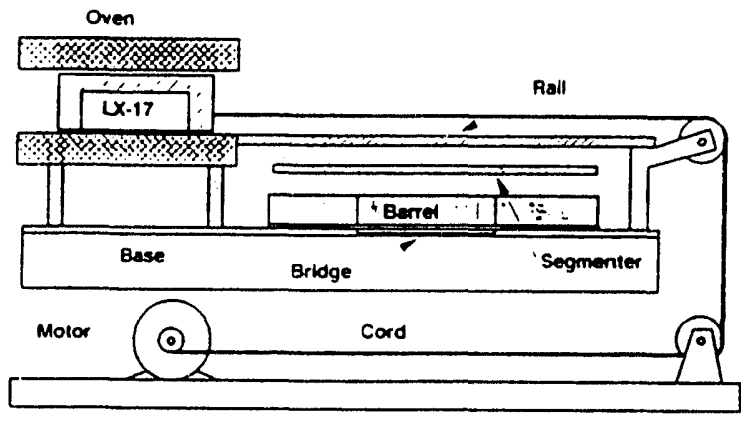

Figure 6. Schematic diagram of the apparatus used to heat and position the heated target over the barrel.

Firing the Shot

When the sample has equilibrated at the desired temperature, the power to the heaters is interrupted by opening the high voltage relay and the bank is charged to the desired firing voltage. The thermal capacity of the fumace and the steel block maintain the temperature while the bank is being charged. The sample block, sliding on steel rails, is then pulled out of the furnace by a string and pulley arrangement and the bank is discharged through the electric gun laminate. About 5 seconds is required to position the sample block over the barrel, so the sample does not cool more than about $1^{\circ} \mathrm{C}$. Detonation of the $\mathrm{HE}$ shatters the block. If the sample does not detonate, the block remains undamaged.

\section{Strip Velocity Calibration Curves}


The first experimental task was to determine the calibration curve for strip velocity vs bank charging voltage. This was done for the $10-\mathrm{mm}$-wide strips using a Fabry-Perot laser velocimeter to measure the strip velocity as a function of time. The calibration curve is shown in Fig. 7. The velocity-time curves can be integrated to give velocity vs distance from which the velocity with which the flyer strikes the $\mathrm{HE}$ can be determined. Since the segmenter simply clips off the edges of the 10-mm-wide strip, the same calibration can be used for the 7-mm and 3-mm-wide strips. The maximum strip velocity of $7.7 \mathrm{~km} / \mathrm{s}$, gives a calculated impact pressure and pulse width of about $55 \mathrm{GPa}$ and 20 ns, respectively.

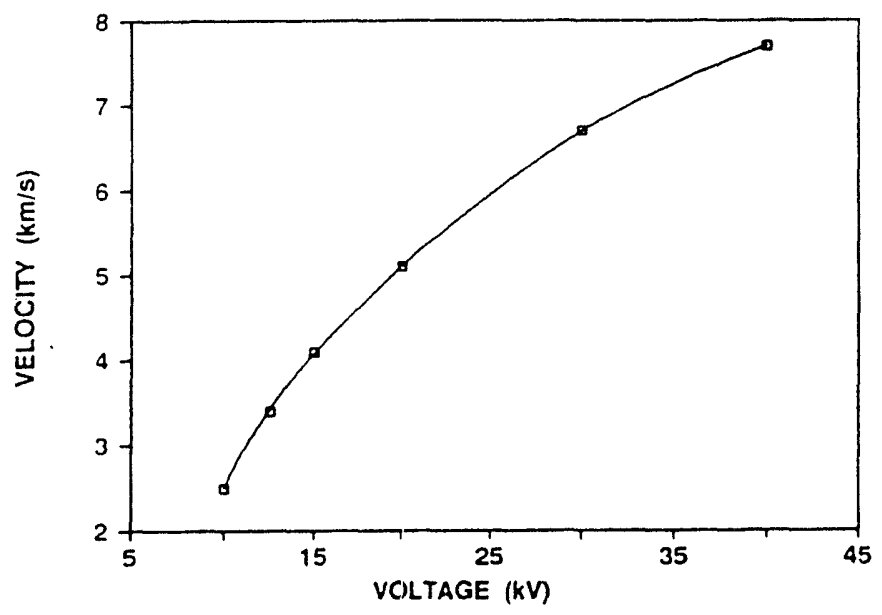

Figure 7. Velocity calibration curve for the strip flyers as a function of bank charging voltage.

\section{Shock Initiation Threshold Measurements}

The objective of the experiments was to determine the shock initiation threshold of $L X-17$ as a function of strip width and temperature. One begins by choosing a firing voltage at which the sample is expected to detonate. If a detonation occurs when the shot is fired, one then chooses a lower voltage. Otherwise, the voltage is raised for the next shot. Succeeding voltages are chosen depending on whether a detonation did or did not occur on the previous shot. For efficiency and for statistical purposes, a protocol must be established for determining the choice of firing voltage. We used a procedure developed by Neyer (1989).

At room temperaure $\left(20^{\circ} \mathrm{C}\right)$ the threshold velocity for the $10-\mathrm{mm}$-wide strips was $5.35 \mathrm{~km} / \mathrm{s}$, in good agreement with the data reported for $2.54-\mathrm{cm}$ diameter flyers by Honodel et al. (1981). We found that we could not initiate the $7 \cdot \mathrm{mm}$-wide strips at the maximum strip velocity of $7.7 \mathrm{~km} / \mathrm{s}$. This finding is consistent with the work of Jackson et al. (1976), who reported that the threshold for 0.25 -mm-thick, round flyers rose sharply when the flyer diameter was reduced below $10 \mathrm{~mm}$.

At $250^{\circ} \mathrm{C}$, the threshold dropped to $3.3 \mathrm{~km} / \mathrm{s}$ for the $10-\mathrm{mm}$ strips. At this temperature, the $\mathrm{LX}-17$ is still less sensitive than a HMX-based explosive at room temperature (PBX-9404 has a velocity threshold of about $2.6 \mathrm{~km} / \mathrm{s}$ for $0.12-\mathrm{mm}$-thick, $2.54-\mathrm{cm}$-diameter, round flyers (Weingart ef al. 1980)). For the 7-mm-wide strips, the threshold was the same as for the $10-\mathrm{mm}$ strip, but the threshold for the 3-mm-wide strips was higher, at $4.85 \mathrm{~km} / \mathrm{s}$. At elevated temperatures, not only does the LX-17 become significantly more sensitive, but the critical area for initiation decreases by at least a factor of 2 ! The decrease in critical area makes the LX17 considerably more vulnerable to shock initiation by explosions of narrow cables and by small, high velocity fragments.

We performed a very limited number of experiments to investigate the shape of the threshold velocity vs temperature curve for the three strip widths.

At $200^{\circ} \mathrm{C}$ the threshold for the 10 -mm-strips rose to $3.7 \mathrm{~km} / \mathrm{s}$ for the $10-\mathrm{mm}$ and $7-\mathrm{mm}$ strips. The threshold at $200^{\circ} \mathrm{C}$ for the $3-\mathrm{mm}$ strips was the same as at $250^{\circ} \mathrm{C}$ to within experimental error. The threshold data are shown graphically in Fig. 8. The error bars indicate the lowest "go" and highest "no-go" at each strip width and temperature.

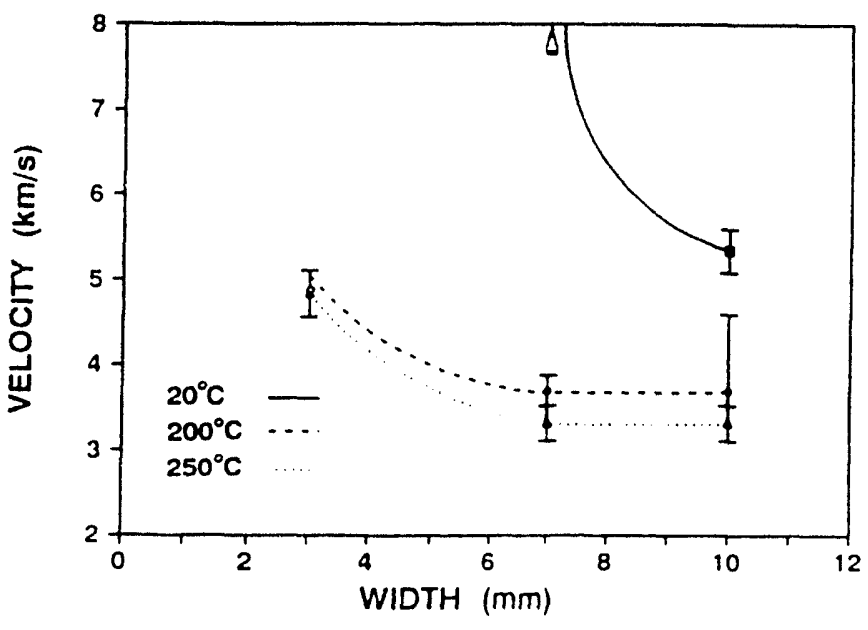

Figure 8. Threshold data summary. The error bars represent the highest "no-go" and the lowest "go". For the 3-mm sample at $200^{\circ} \mathrm{C}$, the lowest "go" was the same as for $250^{\circ}$. More shots would be required to distinguish between the 250 and $200^{\circ}$ points. 
Because we were successful in initiating the LX-17 with 3-mm-wide strips, we performed a final experiment to see whether it was possible to initiate LX -17 by exploding the $\sim 3-\mathrm{mm}$-wide $\mathrm{W}-87$ cables. From the earlier studies of Osher (Osher et al. 1993), we determined that a $2-\mathrm{mm}$ standoff would be a worstcase situation. For larger standoffs, the flyer starts to disintegrate and for smaller standoffs, the velocity is 100 low. We fired a shot with a burst current of about 250 $\mathrm{KA}$, and the $\mathrm{LX}-17$ did not detonate. The reason appears to be that there is a strong magnetic pinching effect that reduces the effective impact width to well below $3 \mathrm{~mm}$. This was verified by an experiment with an aluminum witness block and the same standoff.

\section{References}

H. H. Chau et al., "The Electric Gun, a Versatile Tool for High-Pressure Shock Wave Research, Rev. Sci. Instrum. 51, 1676 (1980).

C. A. Honodel et al., "Sinock Initiation of TATB Formulations", Proc. Seventh Symposium (Int.) on Detonation, NSWC MP 82-334, Naval Surface Weapons Center, White Oak, MD (1981).

R. K. Jackson en al., "Initiation and Detonation Characteristics of TATB", Proc. Sixth Symposium (Int.) on Detonation, ACR-221, Office of Naval Research, Arlington, VA (1976).

B. T. Neyer, "More Efficient Sensitivity Testing", Report MLM-3609, EG\&G Mound Applied Technologies, Miamisburg, OH (1989).

J. E. Osher et al., "Detonator Cable Initiation System Safety Investigation", UCRL-LR-115294,

Lawrence Livermore National Laboratory,

Livermore, $\quad$ CA, to be published (1993).

R. C. Weingart es al., "Acceleration of Thin Flyers by Exploding Metal Foils", Proc. Sixth Symposium (Int.) on Detonation, ACR-221, Office of Naval Research, Arlington, VA (1976).

R. C. Weingart ed al., "Shock Initiation of PBX-9404 by Electrically Driven Flyer Plates", Propellants and Explosives, 5, 158 (1980).

\begin{tabular}{|c|c|c|c|}
\hline Thickness: & $3 \mathrm{~mm}$ & $7 \mathrm{~mm}$ & $10 \mathrm{~mm}$ \\
\hline \multicolumn{4}{|c|}{ Temperature } \\
\hline $20^{\circ} \mathrm{C}$ & & $>7.7 \mathrm{~km} / \mathrm{s}$ & $3.33 \pm 0.2 \mathrm{~km} / \mathrm{s}$ \\
\hline $200^{\circ} \mathrm{C}$ & $4.85 \pm 0.4 \mathrm{~km} / \mathrm{s}$ & $3.7 \pm 0.15 \mathrm{~km} / \mathrm{s}$ & $3.7 \pm 0.15 \mathrm{~km} / \mathrm{s}$ \\
\hline $250^{\circ} \mathrm{C}$ & $4.85 \pm 0.4 \mathrm{~km} / \mathrm{s}$ & $3.33 \pm 0.2 \mathrm{~km} / \mathrm{s}$ & $3.33 \pm 0.2 \mathrm{~km} / \mathrm{s}$ \\
\hline
\end{tabular}

Table I. Velocity initiation thresholds for the impact of 5-cm-long, 0.13-mm-thick Kapton strips impacting LX17. 

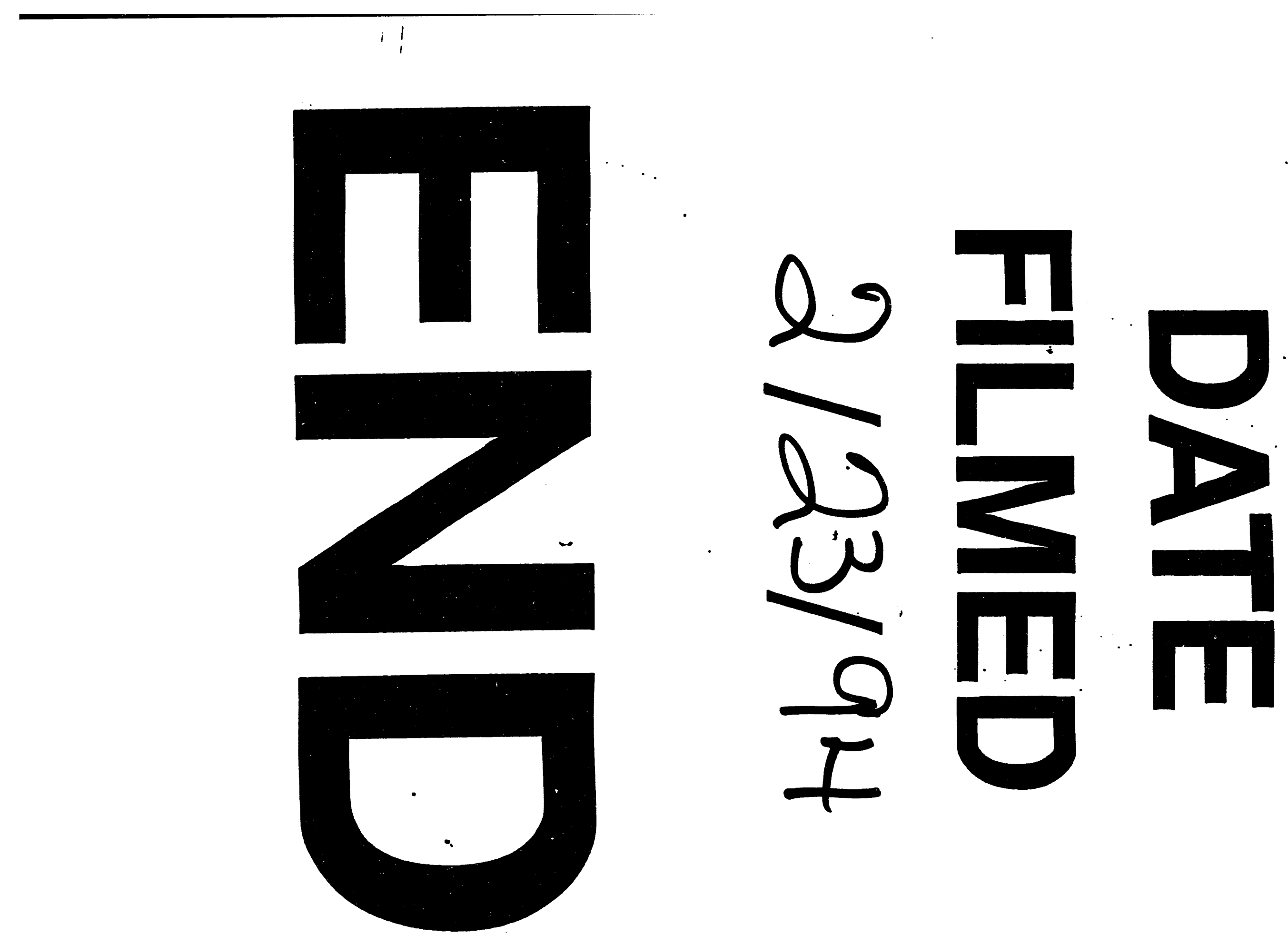
